Communication Study

\title{
Sequence-analysis of video-recorded practitioner-patient communication about smoking in general practice: Do smokers express negative statements about quitting?
}

\author{
Marjolein E.A. Verbiest ${ }^{\text {a,* }}$, Niels H. Chavannes ${ }^{a}$, Esther Passchier ${ }^{a}$, Janneke Noordman ${ }^{\mathrm{b}}$, \\ Margreet Scharloo c, Ad A. Kaptein c , Willem J.J. Assendelft ${ }^{\text {a,d }}$, Mathilde R. Crone ${ }^{\mathrm{a}}$ \\ ${ }^{a}$ Leiden University Medical Centre, Department of Public Health and Primary Care, Leiden, The Netherlands \\ ${ }^{\mathrm{b}}$ Netherlands Institute for Health Services Research, Utrecht, The Netherlands \\ cLeiden University Medical Centre, Department of Medical Psychology, Leiden, The Netherlands \\ ${ }^{\mathrm{d}}$ Radboud University Nijmegen Medical Center, Department of Primary and Community Care, Nijmegen, The Netherlands
}

\section{A R T I C L E I N F O}

\section{Article history:}

Received 17 January 2014

Received in revised form 14 July 2014

Accepted 3 August 2014

\section{Keywords:}

General practice

Smoking cessation

Physician-patient relations

Communication

Video recording

Sequence analysis

\begin{abstract}
A B S T R A C T
Objective: To examine the extent to which smokers express negative statements about quitting and the extent to which these statements influence general practitioners' (GPs') and practice nurses' (PNs') (dis)continuation of guideline-recommended smoking cessation care.

Methods: Fifty-two video-consultations were observed (GP-consultations: 2007-2008; PN-consultations: 2010-2011). Dialogues were transcribed verbatim and professionals' and patients' speech units were coded and analysed using sequential analyses ( $n=1424$ speech units).

Results: GPs focused on asking about smoking (GPs: $42.4 \%$ versus PNs: $26.2 \%, p=0.011$ ) and advising them to quit (GPs: $15.3 \%$ versus PNs: $3.5 \%, p<0.001$ ), whereas PNs focused on assisting them with quitting (GPs: $25.4 \%$ versus PNs: $55.2 \%, p<0.001$ ). Overall, patients expressed more negative statements about quitting than positive statements (negative: $25.3 \%$ versus positive: $11.9 \%, p<0.001$ ), especially when PNs assessed their willingness to quit (OR 3.61,95\% CI 1.44-9.01) or assisted them with quitting (OR 2.23, 95\% CI 1.43-3.48).

Practice implications: An alternative approach to smoking cessation care is proposed in which GPs' tasks are limited to asking, advising, and arranging follow-up. This approach seems the least likely to evoke negative statements of patients about quitting during dialogues with GPs and is compatible with the tasks and skills of PNs who could, subsequently, assist smokers with quitting.
\end{abstract}

(c) 2014 Elsevier Ireland Ltd. All rights reserved.

\section{Introduction}

Evidence-based guidelines for smoking cessation care recommend general practitioners (GPs) and practice nurses (PNs) to routinely ask patients about smoking, advise smokers to quit, assess their motivation to quit, assist them with quitting, and arrange follow-up support [1,2]. A full implementation of these ' 5 As' significantly improves smoking abstinence rates [3-5] and is costeffective [6].

\footnotetext{
* Corresponding author at: Leiden University Medical Centre, Department of Public Health and Primary Care, P.O. Box 9600, 2300 RC Leiden, The Netherlands. Tel.: +31 71 5268456; fax: +31 715268259

E-mail address: m.e.a.verbiest@lumc.nl (Marjolein E.A. Verbiest).
}

Nevertheless, GPs and PNs (see Appendix 1 for a description of PNs' role in Dutch general practice) report various barriers to the implementation of these guidelines during routine consultation [7-12]. Although patients state that they are willing to discuss their smoking behaviour during a practitioner-initiated dialogue [13], GPs and PNs report that smokers regularly express negative statements regarding quitting during unsolicited dialogues about smoking, such as a lack of motivation or discipline to quit [7-12]. These negative statements about quitting impede a structural implementation of guideline-recommended smoking cessation care [7-12]. GPs report a limited range of skills for dealing with these negative statements [8] and consequently tend to avoid these negative statements to preserve a good doctor-patient relationship $[14,15]$. This factor is one of the reported reasons for the gap in evidence-based practice regarding the provision of 
guideline-recommended smoking cessation care in Dutch general practice. The results show that, for example, $79 \%$ of all smokers and $40 \%$ of smokers who discuss smoking with their GP do not receive advice regarding quitting smoking [16]. Therefore, we aim to provide more insight into the interaction between primary care professionals and smokers during unsolicited dialogues about smoking. These insights may result in recommendations for primary care professionals for how to address smokers' negative statements regarding quitting and help them to fully implement guideline-recommended smoking cessation care.

Until now, very few studies have examined the interaction between primary care professionals and smokers. Previous studies have focused on the way patients react if GPs link their health issues to their smoking [17] or if they are counselled to quit smoking based on their readiness to quit [18]. According to our knowledge, no studies have examined the responses of smokers if professionals apply a guideline for smoking cessation care. Moreover, the impact of these responses on professionals' continuation of guideline adherence is unknown. More insight into this interaction may contribute to strategies that can benefit the implementation of smoking cessation counselling in general practice.

Therefore, we assessed the extent to which: (i) professionals use the 5 As for smoking cessation care, (ii) patients who smoke express negative or positive statements about quitting if professionals use these $5 \mathrm{As}$, and (iii) professionals continue or discontinue their use of the 5 As after patients express a positive or negative statement about quitting. Based on the literature, we hypothesised that an unsolicited conversation about smoking would cause negative statements from patients about quitting. Furthermore, we hypothesised that patients' negative statements about quitting would hamper the continuation of guideline adherence, whereas patients' positive statements about quitting would facilitate it. Because knowledge and skills regarding lifestyle counselling are highlighted in the 'competence profile' of PNs [19], we hypothesised that patients' negative statements about quitting would be less likely to hamper guideline adherence in dialogues with PNs compared to dialogues with GPs.

\section{Methods}

\subsection{Study setting, participants and design}

A cross-sectional study was conducted in which we examined video-recordings of random real-life routine consultations in general practice. Video-taped consultations are regularly used to observe lifestyle counselling [20-25] and can provide a complete record of what actually happens during consultations and be viewed repeatedly [26]. Videos were collected (nationwide) and archived by the Netherlands Institute for Health Services Research (NIVEL). Consultations with GPs and PNs were recorded during 2007-2008 and during 2010-2011, respectively. Details of data collection are reported elsewhere $[27,28]$.

All video-recordings in which smoking was discussed $(n=211)$ were selected for the present study. We excluded the videorecordings of consultations with non-smokers $(n=63)$, ex-smokers $(n=70)$ and consultations in which the patient specifically requested smoking cessation assistance $(n=13)$ or addressed smoking on their own initiative $(n=13)$. This removal resulted in a set of 52 videos of 33 primary care professionals (17 GPs and 16 PNs). All of the PNs were trained in motivational interviewing during a previous study [28]. This training was not conducted for GPs, and it is unclear whether the participating GPs were trained in motivational interviewing prior to the study. All of the GPs, PNs and patients were unaware of the fact that the recordings and analyses would focus on smoking cessation care.
This study was conducted according to the Dutch legislation on privacy, for which approval of the local medical ethics committees was not required [29].

\subsection{Procedure and measurements}

After the patients gave their informed consent, consultations were recorded. Two researchers observed the video-recordings. Subsequently, the dialogues between professionals and patients about smoking were transcribed verbatim (MV and EP). A coding scheme was developed for each speech unit of patients and professionals. A speech unit is defined as 'the smallest distinguishable speech segment to which a classification may be assigned' [30]. The length of a speech unit can vary from a single word to a lengthy sentence.

\subsubsection{Professionals' speech units}

We coded the speech units of professionals that were related to the core components of the guideline for smoking cessation care ( 5 As). These included: (1) Ask (about the patient's smoking status, the number of cigarettes, or smoking history), (2) Advise (the patient to quit smoking or to smoke less), (3) Assess (the smoker's motivation to quit), (4) Assist (the patient with quitting, which includes discussing the advantages of quitting smoking, risks of smoking, barriers to quitting, support options, pharmacological support, or a quit plan), and (5) Arrange (follow-up with support for quitting smoking with the patient, including referring the smoker to behavioural quit support, arrange a telephone follow-up, or ask permission to discuss smoking the next time). Appendix 2 provides an overview of the coding scheme, which is illustrated by examples of the speech units.

\subsubsection{Patients' speech units}

We coded both negative and positive statements about smoking cessation as expressed by the patients. A negative statement included: (1) barriers to quit, (2) disadvantages of quitting, (3) advantages of smoking, and (4) reasons to relapse. Patients' positive statements included: (1) motivators to quit, (2) advantages of quitting, (3) disadvantages of smoking, and (4) reasons to smoke less or continue abstinence (see Appendix 2 for coding scheme).

\subsubsection{Other speech units}

The speech units of professionals that we did not code as being related to the $5 A$ s and speech units of patients that we did not code as negative or positive statements about quitting were coded as follows: (1) other (non-)smoke-related questions/answers, e.g., "I smoke 10 cigarettes per day"; (2) other (non-)smoke-related information, e.g., "These complaints might result from your smoking"; (3) other (non-)smoke-related confirmations, e.g., "Yes, I agree"; and (4) other (non-) smoke-related speech units, e.g., "Thank you". In contrast to the '5A-related' speech units, 'other smoke-related' speech units of professionals included general statements about smoking and its risks and were unrelated to quitting or the patient's motivation to quit (see Appendix 2 for coding scheme).

\subsubsection{Inter-rater agreement}

Two researchers (MV and $M C$ ) independently coded five randomly selected dialogues (a total of 153 speech units) that resulted in moderate inter-rater agreement (kappa 0.66). During this pre-test of our coding scheme, we encountered two coding difficulties. First, some disagreements occurred regarding differentiating between the speech units of professionals related to 'Assisting a quit attempt' and to 'providing smoke-related information'. These disagreements were resolved by a third person 
(NC), and we decided to code a speech unit solely as 'Assisting a quit attempt' if it was related to the patient's motivation to quit, such as an exploration of barriers and motivators to quit, e.g., "Can you tell me a bit more about the reasons why you want to quit?". If professionals only made general statements about smoking unrelated to quitting or the patient's motivation to quit, we coded the speech unit as 'other, smoke-related: the provision of smokerelated information', e.g., "Your smoking has an impact on your vocal cords".

Second, the pre-test showed that the number of coding categories for patients' negative and positive statements about smoking cessation was too limited (it originally included only the coding categories 'barriers to quit' and 'motivators to quit'). After consulting with a third person (NC), we decided to extend these coding categories to include '(dis)advantages of quitting', '(dis)advantages of smoking', 'reasons to relapse', and 'reasons to smoke less or continue abstinence'.

The remaining transcripts were coded by one researcher (MV) (see Appendix 2 for coding scheme).

\subsection{Statistical analyses}

First, we calculated the total number of speech units of both professionals and patients and the number of speech units per dialogue. Differences between GP and PN dialogues were analysed with a Chi-square test.

Second, we performed sequential analyses that can be defined as ' $a$ set of techniques used to identify temporal patterns embedded within sequences of coded behaviours or stimulus events' [31-33]. The main aim of sequential analysis is to determine whether a particular sequence of behaviours or events occurs to a greater or lesser extent than can be expected by chance alone [31,32]. This type of analysis can be regarded as a suitable method to explore interaction patterns between healthcare professionals and patients [31].

We prepared our data for these analyses by forming a chain of codes representing the speech units of professionals and patients (a total of 1424 speech units). Then, we examined the three speech units (three lags) following each 5A-related speech unit for negative and positive statements of smokers about quitting. The existing literature provides only a few indications for the optimal number of lags [30,31]. However, because we focused on the immediate responses of patients on the provision of smoking cessation care, we limited our analyses to three lags. Lag 0 represents the 5A-related speech unit of a professional during the dialogue; lag 1 represents the speech unit of the patient immediately following the professional's 5A-related speech unit at lag 0 ; lag 2 represents the second speech unit of the patient following the professional's 5A-related speech unit at lag 0 ; and lag 3 represents the third speech unit of the patient following the professional's 5A-related speech unit at lag 0.

Next, we calculated transitional probabilities, i.e., the likelihood that a patient expressed one or more negative and positive statements regarding quitting within the three lags following a $5 \mathrm{~A}-$ related speech unit of the professional (see Appendix 3). The transitional probabilities were uncorrected for the potential clustering effects of speech units within the dialogue. Therefore, we used generalised estimating equations to consider the multilevel structure of the data. This approach resulted in corrected odds ratios (ORs) (e.g., the likelihood that a negative or positive statement of the smoker about quitting was preceded by a $5 \mathrm{~A}$-related speech unit of the professional compared to any other preceding category of speech units of professionals).

The same method was used to compute the likelihood that a negative or positive statement about the patient quitting smoking was followed within 3 lags by one or more 5A-related, othersmoke-related or non-smoke-related speech units of the professional.

\section{Results}

\subsection{Sample characteristics}

Table 1 shows the duration of the consultations and dialogues about smoking and the characteristics of the patients, GPs and PNs who were enrolled in the study. In total, we coded 1424 speech units (mean 27.4 speech units per smoking dialogue, range 4-118), of which 727 were of professionals (51.1\%, mean 14.0 speech units per smoking dialogue, range 2-55) and 697 were of patients $(48.9 \%$, mean 13.4 speech units per smoking dialogue, range $1-63)$.

Table 1

Characteristics of the video-recorded consultations between patients, GPs and PNs.

\begin{tabular}{|c|c|c|c|}
\hline & \multicolumn{3}{|c|}{ Dialogues with } \\
\hline & Total $(n=52)$ & GPs $(n=20)$ & PNs $(n=32)$ \\
\hline \multicolumn{4}{|l|}{ Consultation characteristics } \\
\hline Total duration (min), M (SD) & $22: 41(12: 05)$ & $12: 29(4: 21)$ & 29:04 (10:56) \\
\hline Duration of smoking dialogue (min), M (SD) & $2: 57(2: 53)$ & $1: 28(1: 04)$ & $3: 53(3: 17)$ \\
\hline \multicolumn{4}{|l|}{ Patient characteristics } \\
\hline Age in years, $\mathrm{M}(\mathrm{SD})$ & $53.5(14.8)$ & $46.1(15.7)$ & $57.7(12.6)$ \\
\hline Gender, female & $23(44.2 \%)$ & $9(45.0 \%)$ & $14(43.8 \%)$ \\
\hline \multicolumn{4}{|l|}{ Educational level } \\
\hline Low & $11(21.2 \%)$ & $3(15.0 \%)$ & $8(25.0 \%)$ \\
\hline Middle & $29(55.8 \%)$ & $8(40.0 \%)$ & $21(65.6 \%)$ \\
\hline High & $3(5.8 \%)$ & $2(10.0 \%)$ & $1(3.1 \%)$ \\
\hline \multicolumn{4}{|l|}{ Reason for consultation } \\
\hline Respiratory & $16(30.8 \%)$ & $8(40.0 \%)$ & $8(25.0 \%)$ \\
\hline Cardiovascular & $14(26.9 \%)$ & $6(30.0 \%)$ & $8(25.0 \%)$ \\
\hline Diabetes mellitus & $9(17.3 \%)$ & $0(0.0 \%)$ & $9(28.1 \%)$ \\
\hline Multiple smoke-related & $10(19.2 \%)$ & $3(15.0 \%)$ & $7(21.9 \%)$ \\
\hline Other smoke-related & $1(1.9 \%)$ & $1(5.0 \%)$ & $0(0.0 \%)$ \\
\hline Non-smoke-related & $2(3.8 \%)$ & $2(10.0 \%)$ & $0(0.0 \%)$ \\
\hline Professional characteristics & Total $(n=33)$ & GPs $(n=17)$ & PNs $(n=16)$ \\
\hline Age in years, M (SD) & $46.4(7.1)$ & $49.9(6.1)$ & $42.4(6.2)$ \\
\hline Gender, female & $22(66.7 \%)$ & $6(35.3 \%)$ & $16(100.0 \%)$ \\
\hline
\end{tabular}

GP, general practitioner; PN, practice nurse; M, mean; SD, standard deviation. 


\subsection{Speech units}

\subsubsection{Professionals' smoking cessation care}

Overall, half of the speech units of professionals were related to the 5 As for smoking cessation care (Table 2). Chi-square tests showed that the PNs expressed significantly more speech units related to these five As than GPs (GPs: $37.8 \%$ versus PNs: $55.2 \%$; $p<0.001$ ). Within this category, GPs asked patients significantly more often about smoking and advised more patients to quit compared to the PNs. The PNs assisted significantly more patients with quitting compared to GPs.

The remaining speech units of professionals were coded as 'other smoke-related' speech units (31.4\%) and 'other non-smokerelated' speech units (17.2\%). Although, no significant differences were found in these coding categories between GPs and PNS, we found a significant difference in one of the subcategories of "other smoke-related' speech units: GPs provided significantly more general smoke-related information compared to the PNs (GPs: $37.0 \%$ versus PNs: $12.6 \%, p<0.001$; data not shown).

\subsubsection{Patients' statements about smoking cessation}

Overall, patients expressed significantly more negative statements than positive statements about quitting during an unsolicited dialogue about smoking (negative: $25.3 \%$ versus positive: $11.9 \% ; p<0.001$ ). No significant differences were found between the number of negative statements during dialogues with PNs compared to dialogues with GPs (Table 2).

A relatively large number of patients' speech units were coded as 'other smoke-related' (49.2\%). This category was composed of numerous simple answers to and confirmations of the provision of smoke-related questions and information of the professional, e.g., "Yes, I smoke" or "Yes, I agree".

\subsection{Sequential analysis}

Table 3 shows the transitional probabilities that smokers expressed negative or positive statements about quitting following the $5 \mathrm{~A}$ speech units of professionals. Overall, patients were more likely to express a negative than a positive statement, irrespective of the preceding $5 \mathrm{~A}$. The probability that smokers would express a negative statement about quitting was lowest if professionals asked about smoking (11\%) or arranged a follow-up (15\%) and highest if professionals assessed the smoker's motivation to quit (55\%) or provided assistance with quitting (38\%).

After adjusting for clustering effects, patients were significantly more likely to express a negative statement about quitting if professionals preceded their response with a speech unit related to assessing the patient's motivation to quit (OR 3.61, 95\% CI $1.44-9.01$ ) or assisted the patient with quitting (OR $2.23,95 \% \mathrm{CI}$ 1.43-3.48) compared to any other preceding speech unit of professionals. If professionals used a speech unit related to providing assistance with quitting, patients were also significantly more likely to express a positive statement about quitting (OR 2.76, 95\% CI 1.56-4.89) compared to any other preceding speech unit of professionals. Table 4 shows the results of these analyses, separately for the GP and PN dialogues. The above-mentioned effects were found only in the PN dialogues. Because of the sparseness of the data, it was not possible to compute all corrected ORs in the GP and PN dialogues (Table 4).

Fig. 1 shows the transitional probabilities for the case that GPs and PNs expressed a 5A-related, other smoke-related, or nonsmoke-related speech unit following patients' negative and positive statements about quitting. Although we observed that GPs were less likely to continue using the 5 As following patients' negative statements compared to preceding positive statements (negative: $19 \%$ versus positive: $47 \%$ ), the analyses did not confirm this finding (OR 0.68, 95\% CI 0.17-2.75).

\section{Discussion}

\subsection{Main findings}

The present study aimed to provide insight into the professional-patient interaction during unsolicited dialogues about smoking. First, we assessed the extent to which primary care professionals use the 5As for smoking cessation care during unsolicited dialogue about smoking. We found that GPs mainly focused on asking their patients about smoking and PNs on assisting patients with a quit attempt. Overall, little attention was paid to advising smokers to quit, to assessing their motivation to quit, and to arranging followup. Second, we examined the extent to which smokers expressed positive and negative statements about quitting during these dialogues. Overall, we found that patients more frequently expressed negative statements compared to positive statements

Table 2

Total number of the coded speech units of patients and professionals and the difference between GPs and PNs.

\begin{tabular}{|c|c|c|c|c|c|c|c|c|c|c|c|c|c|}
\hline & \multicolumn{4}{|c|}{ Total coded speech units $(n=1424)$} & \multicolumn{4}{|c|}{ GPs' coded speech units $(n=287)$} & \multicolumn{4}{|c|}{ ]PNs' coded speech units $(n=1137)$} & \multirow[b]{2}{*}{$p^{a}$} \\
\hline & Number/Total & Mean & Range & $\%$ & Number/Total & Mean & Range & $\%$ & Number/Total & Mean & Range & $\%$ & \\
\hline \multicolumn{14}{|l|}{ Professionals } \\
\hline Total & $727 / 1424$ & 14.0 & $2-55$ & 51.1 & $156 / 287$ & 14.4 & $2-15$ & 54.4 & $571 / 1137$ & 35.5 & $2-55$ & 50.2 & 0.210 \\
\hline Other SR & $228 / 727$ & 4.4 & $0-22$ & 31.4 & $54 / 156$ & 2.7 & $0-9$ & 34.6 & $174 / 571$ & 5.4 & $0-22$ & 30.5 & 0.323 \\
\hline Other NSR & $125 / 727$ & 2.4 & $0-16$ & 17.2 & $43 / 156$ & 2.2 & $0-7$ & 27.6 & $82 / 571$ & 2.6 & $0-16$ & 14.4 & $<0.001$ \\
\hline $5 \mathrm{As}$ & $374 / 727$ & 7.2 & $1-33$ & 51.4 & $59 / 156$ & 3.0 & $1-9$ & 37.8 & $315 / 571$ & 9.8 & $1-33$ & 55.2 & $<0.001$ \\
\hline Ask & $107 / 374$ & 2.1 & $0-6$ & 28.6 & $25 / 59$ & 1.3 & $0-3$ & 42.4 & $82 / 315$ & 2.6 & $1-6$ & 26.0 & 0.011 \\
\hline Advise & $20 / 374$ & 0.4 & $0-6$ & 5.4 & $9 / 59$ & 0.5 & $0-3$ & 15.3 & $11 / 315$ & 0.3 & $0-6$ & 3.5 & $<0.001$ \\
\hline Assess & $43 / 374$ & 0.8 & $0-4$ & 11.5 & $8 / 59$ & 0.4 & $0-2$ & 13.6 & $35 / 315$ & 1.1 & $0-4$ & 11.1 & 0.588 \\
\hline Assist & $189 / 374$ & 3.6 & $0-22$ & 50.5 & $15 / 59$ & 0.8 & $0-7$ & 25.4 & $174 / 315$ & 5.4 & $0-22$ & 55.2 & $<0.001$ \\
\hline Arrange & $15 / 374$ & 0.3 & $0-4$ & 4.0 & $2 / 59$ & 0.1 & $0-1$ & 0.03 & $13 / 315$ & 0.4 & $0-4$ & 4.1 & 0.791 \\
\hline \multicolumn{14}{|l|}{ Patients } \\
\hline Total & $697 / 1424$ & 13.4 & $1-63$ & 48.9 & $131 / 287$ & 6.6 & $1-16$ & 45.6 & $566 / 1137$ & 17.7 & $1-63$ & 49.8 & 0.210 \\
\hline Other SR & $343 / 697$ & 6.6 & $1-32$ & 49.2 & $63 / 131$ & 3.2 & $1-7$ & 48.1 & $280 / 566$ & 8.8 & $1-32$ & 49.5 & 0.776 \\
\hline Other NSR & $95 / 697$ & 1.8 & $0-15$ & 13.6 & $29 / 131$ & 1.5 & $0-5$ & 22.1 & $66 / 566$ & 2.1 & $0-15$ & 11.7 & 0.002 \\
\hline $\begin{array}{l}\text { Negative statements } \\
\text { about quitting }\end{array}$ & $176 / 697$ & 3.4 & $0-13$ & 25.3 & $25 / 131$ & 1.3 & $0-7$ & 19.1 & $151 / 566$ & 4.7 & $0-13$ & 26.7 & 0.071 \\
\hline $\begin{array}{l}\text { Positive statements } \\
\text { about quitting }\end{array}$ & $83 / 697$ & 1.6 & $0-8$ & 11.9 & $14 / 131$ & 0.7 & $0-4$ & 10.7 & $69 / 566$ & 2.2 & $0-8$ & 12.2 & 0.632 \\
\hline
\end{tabular}

GPs, general practitioner; PNs, practice nurse; SR, smoke-related; NSR, non-smoke-related.

a Differences in the proportion of coded speech units between GP and PN dialogues were calculated with $\chi^{2}$ tests. 
Table 3

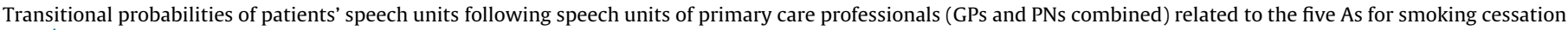
care $^{\mathrm{a}, \mathrm{b}}$.

\begin{tabular}{|c|c|c|c|c|c|c|c|c|}
\hline \multirow{3}{*}{$\begin{array}{l}\text { Professionals' } \\
5 \text {-A speech } \\
\text { unit (lag 0) }\end{array}$} & \multicolumn{8}{|c|}{ Patients' speech units (lag 1-3) } \\
\hline & \multicolumn{2}{|c|}{$\begin{array}{l}\text { Negative statement } \\
\text { about quitting }\end{array}$} & \multicolumn{2}{|c|}{$\begin{array}{l}\text { Positive statement } \\
\text { about quitting }\end{array}$} & \multicolumn{2}{|c|}{$\begin{array}{l}\text { Other smoke-related } \\
\text { speech unit }\end{array}$} & \multicolumn{2}{|c|}{$\begin{array}{l}\text { Non-smoke-related } \\
\text { speech unit }\end{array}$} \\
\hline & Probability & OR (95\% CI) & Probability & OR $(95 \% \mathrm{CI})$ & Probability & OR $(95 \% \mathrm{CI})$ & Probability & OR (95\% CI) \\
\hline All 5 As & $0.31(149 / 476)$ & $1.88(1.30-2.72)^{* *}$ & $0.09(41 / 476)$ & $1.78(1.07-2.97)^{*}$ & $0.53(250 / 476)$ & $3.01(2.00-4.54)^{* *}$ & $0.08(36 / 476)$ & $0.42(0.29-0.59)^{* *}$ \\
\hline Ask & $0.11(16 / 142)$ & $1.06(0.61-1.84)$ & $0.01(2 / 142)$ & $0.66(0.26-1.64)$ & $0.83(118 / 142)$ & $11.30(3.68-34.65)^{* * *}$ & $0.04(6 / 142)$ & $0.24(1.13-1.45)^{* *}$ \\
\hline Advise & $0.27(3 / 11)$ & $0.86(0.19-3.94)$ & $0.10(1 / 11)$ & - & $0.36(4 / 11)$ & $1.17(0.34-3.98)$ & $0.27(3 / 11)$ & $0.68(0.24-2.27)$ \\
\hline Assess & $0.55(35 / 63)$ & $3.61(1.44-9.01)^{*}$ & $0.13(8 / 63)$ & $2.87(0.89-9.27)$ & $0.27(17 / 63)$ & $1.98(0.58-6.57)$ & $0.05(3 / 63)$ & $0.43(0.13-1.39)$ \\
\hline Assist & $0.38(93 / 247)$ & $2.23(1.43-3.48)^{* * *}$ & $0.12(30 / 247)$ & $2.76(1.56-4.89)^{* * *}$ & $0.41(102 / 247)$ & $1.64(1.00-2.68)^{*}$ & $0.09(22 / 247)$ & $0.70(0.45-1.07)$ \\
\hline Arrange & $0.15(2 / 13)$ & $-{ }^{\mathrm{c}}$ & $0.00(0 / 13)$ & - & $0.69(9 / 13)$ & $1.08(0.26-4.44)$ & $0.15(2 / 13)$ & $0.78(0.20-3.06)$ \\
\hline Other SR & $0.30(89 / 293)$ & $2.44(1.62-3.66)^{* *}$ & $0.12(35 / 293)$ & $3.46(2.01-5.93)^{* *}$ & $0.48(140 / 293)$ & $1.55(1.02-2.37)^{*}$ & $0.11(32 / 293)$ & $0.81(0.56-1.17)$ \\
\hline
\end{tabular}

about quitting. These negative statements mainly consisted of barriers to quitting smoking and were most likely expressed if PNs assessed the patients' willingness to quit or if PNs assisted patients with a quit attempt. Finally, we explored the extent to which primary care professionals (dis)continued the 5 As following patients' positive or negative statements about quitting. Although we observed that GPs were less likely to continue using the 5 As following patients' negative statements about quitting, the analyses did not confirm this finding.

\subsection{Interpretation of the findings}

Consistent with previous studies and assumptions underlying current guidelines, we found that GPs and PNs focus on different smoking cessation counselling activities [1,20,21,34,35]. GPs tend to focus on identifying smokers and informing about risks, whereas stop-smoking support is more often provided by PNs. Although these differences might be explained by the different time periods during which the consultations were recorded (GPs: 2007-2008, PNs: 2010-2011), it is more likely that these differences can be explained by other factors, such as differences in patient populations, characteristics of the professionals (e.g., training, skills, practice protocols), and consultation characteristics (e.g., available time).

Both GPs and PNs lacked focus on arranging a follow-up for quitsmoking support. This is consistent with recent findings showing that GPs in the Netherlands experience a lack of awareness of smoking cessation programmes in their neighbourhood [12].

Table 4

Transitional probabilities of patients' speech units following the speech units of GPs and PNs separately related to the five As for smoking cessation care ${ }^{\mathrm{a}, \mathrm{b}}$.

\begin{tabular}{|c|c|c|c|c|c|c|c|c|}
\hline & \multicolumn{8}{|c|}{ Patients' speech units (lag 1-3) } \\
\hline & \multicolumn{2}{|c|}{ Negative statement about quitting } & \multicolumn{2}{|c|}{ Positive statement about quitting } & \multicolumn{2}{|c|}{ Other smoke-related speech unit } & \multicolumn{2}{|c|}{$\begin{array}{l}\text { Other non-smoke-related } \\
\text { speech unit }\end{array}$} \\
\hline & Probability & OR $(95 \% \mathrm{CI})$ & Probability & OR (95\% CI) & Probability & OR $(95 \% \mathrm{CI})$ & Probability & OR (95\% CI) \\
\hline \multicolumn{9}{|c|}{ GPs' 5-A speech units (lag 0) } \\
\hline All 5As & $0.23(17 / 75)$ & $1.71(0.71-4.12)$ & $0.12(9 / 75)$ & $0.79(0.18-3.54)$ & $0.56(42 / 75)$ & $7.01(2.50-19.67)^{* *}$ & $0.09(7 / 75)$ & $0.24(0.11-0.54)^{* *}$ \\
\hline Ask & $0.08(3 / 38)$ & $1.65(0.58-4.75)$ & $0.03(1 / 38)$ & $0.84(0.13-5.32)$ & $0.79(30 / 38)$ & $8.79(1.97-39.34)^{*}$ & $0.11(4 / 38)^{*}$ & $0.29(0.11-0.78)^{*}$ \\
\hline Advise & $0.50(3 / 6)$ & $2.32(0.20-26.66)$ & $0.17(1 / 6)$ & - & $0.33(2 / 6)$ & - & $0.00(0 / 6)$ & - \\
\hline Assess & $0.63(5 / 8)$ & $--^{c}$ & $0.25(2 / 8)$ & - & $0.00(0 / 8)$ & $1.88(0.08-42.27)$ & $0.13(1 / 8)$ & $0.48(0.02-9.59)$ \\
\hline Assist & $0.27(6 / 22)$ & $1.59(0.33-7.06)$ & $0.23(5 / 22)$ & - & $0.41(9 / 22)$ & $3.36(0.61-18.45)$ & $0.10(2 / 22)$ & $0.29(0.06-1.42)$ \\
\hline Arrange & $0.00(0 / 1)$ & - & $0.00(0 / 1)$ & - & $10.00(1 / 1)$ & - & $0.00(0 / 1)$ & - \\
\hline Other SR & $0.19(12 / 59)$ & $1.96(0.87-4.44)$ & $0.07(4 / 59)$ & $2.81(0.84-9.37)$ & $0.55(34 / 59)$ & $1.81(0.88-3.73)$ & $0.19(9 / 59)$ & $0.71(0.36-1.38)$ \\
\hline \multicolumn{9}{|c|}{ PNs' 5-A speech units (lag 0) } \\
\hline All 5 As & $0.33(132 / 401)$ & $1.91(1.28-2.85)^{*}$ & $0.08(32 / 401)$ & $2.02(1.16-3.54)^{*}$ & $0.52(208 / 401)$ & $2.59(1.57-4.26)^{* *}$ & $0.07(29 / 401)$ & $0.46(0.30-0.69)^{* *}$ \\
\hline Ask & $0.13(13 / 104)$ & $1.01(0.54-1.89)$ & $0.01(1 / 104)$ & $0.65(0.23-1.81)$ & $0.85(88 / 104)$ & $17.06(8.29-35.11)^{* *}$ & $0.02(2 / 104)$ & $1.15(0.05-0.43)^{* *}$ \\
\hline Advise & $0.00(0 / 5)$ & $0.51(0.06-4.00)$ & $0.00(0 / 5)$ & - & $0.40(2 / 5)$ & $0.69(0.18-2.60)$ & $0.60(3 / 5)$ & $1.13(0.31-4.14)$ \\
\hline Assess & $0.55(30 / 55)$ & $4.37(1.69-11.30)^{*}$ & $0.11(6 / 55)$ & $2.24(0.60-8.36)$ & $0.31(17 / 55)$ & $2.24(0.46-10.87)$ & $0.04(2 / 55)$ & $0.36(0.08-1.67)$ \\
\hline Assist & $0.39(87 / 225)$ & $2.20(1.3803 .51)^{* * *}$ & $0.11(25 / 225)$ & $3.17(0.74-5.76)^{* *}$ & $0.41(93 / 225)$ & $1.50(0.85-2.66)$ & $0.09(20 / 225)$ & $0.77(0.47-1.26)$ \\
\hline Arrange & $0.17(2 / 12)$ & - & $0.00(0 / 12)$ & - & $0.67(8 / 12)$ & $0.99(0.19-5.14)$ & $0.17(2 / 12)$ & $0.81(0.17-3.95)$ \\
\hline Other SR & $0.33(77 / 234)$ & $2.75(1.75-4.32)^{* *}$ & $0.13(31 / 234)$ & $3.93(2.17-7.15)^{* *}$ & $0.45(106 / 234)$ & $1.57(0.89-2.76)$ & $0.09(20 / 234)$ & $0.82(0.51-1.32)$ \\
\hline
\end{tabular}

GPs, general practitioners; PNs, practice nurses.

$p<0.05$

$p<0.001$

a Transitional probabilities represent the probabilities of speech chains that begin with the event indicated as 'professionals' 5-A speech unit' and ending with the specific

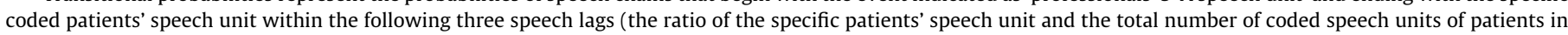
brackets).

b Generalised estimating equations (GEE) corrected for the hierarchical structure of the data.

c Analyses not possible due to data sparseness. 


\section{Five As}

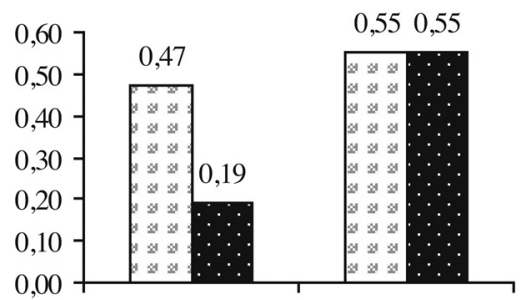

GP

PN

(1)

II. Other smoke-related

III. Non-smoke-related

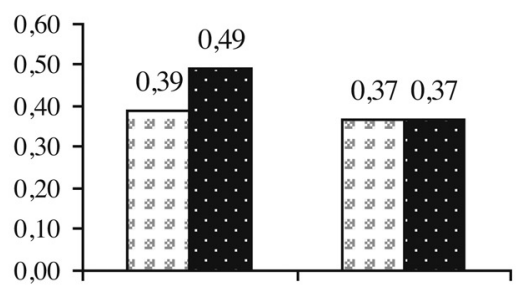

GP

PN

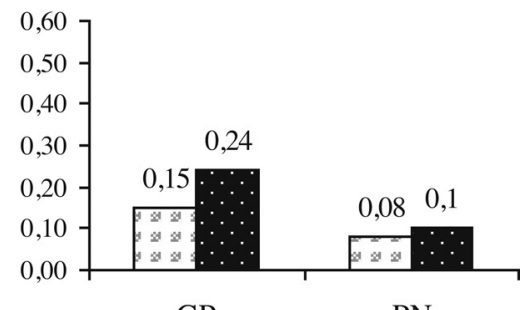

GP

$\mathrm{PN}$

\section{$\square$ Positive Negative}

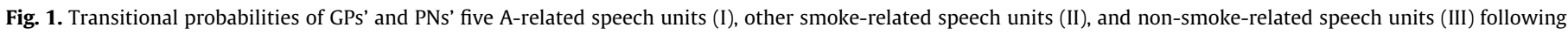
patients' positive and negative statements about quitting smoking.

Additionally, smokers may lack the motivation to quit, which seems to be a logical reason for not arranging follow-up care. However, even if smokers are not motivated to quit, guidelines recommend primary care professionals to ask the patient's permission to discuss their smoking behaviour at the next consultation. Therefore, in the present study, if GPs and PNs had followed these current guidelines, the rate of arranging follow-up would probably have been much higher than that observed.

Although not statistically confirmed, we observed that GPs were less likely to proceed with a 5A-related speech unit following a negative statement of patients about quitting, whereas this approach was not observed in the dialogues with the PNs. A possible explanation for this difference is that all PNs in the present study were trained in motivational interviewing, and GPs might lack these skills or have insufficient time to apply them [36,37]. This difference might also explain why patients were more likely to respond both negatively and positively towards quitting during dialogues with PNs; exploring and resolving patients' ambivalence towards behaviour change is an essential part of motivational interviewing [38]. Another explanation might be that GPs and PNs encounter various types of patients. For example, patients who visit the GP might be more likely to perceive their complaints as not directly related to their smoking behaviour, resulting in less motivation to quit or discuss smoking. PNs provide care for patients with diabetes mellitus, asthma, or COPD, including routinely providing information, advice and counselling on lifestyle. These patients might be more inclined to relate their health complaints to their smoking behaviour, which might result in a higher level of motivation to quit or discuss smoking.

\subsection{Study strengths and limitations}

Video-based observations provide an objective method to capture all of the modalities of the interaction between professionals and patients [26]. Additionally, sequence analysis exceeds a simple description of frequencies of spoken communication and provides further insight into the practitioner-patient interaction process. According to our knowledge, this study is the first to use sequence analysis to provide insight into the way smoking cessation care evokes positive and negative responses of patients, thereby providing further insight into the practitioner-patient interaction process.

However, the study also has several limitations. First, to guarantee the anonymity of the patients, the camera was positioned so that patients were only visible from behind or not visible at all. Therefore, we were unable to observe nonverbal behaviour, which may also play a role in assessing patients' responses towards smoking cessation. However, a recent study showed that communication ratings using only audio or video data are highly correlated [39]. Second, because of the small sample, it was not always possible to consider the possible cluster effects within the data. Third, the use of videobased observations may limit the external validity of the findings, unless the sample is representative of the overall population [26]. Although we were unable to compare our sample of PNs with the average Dutch population of PNs, the GPs in our study were representative of the average Dutch population of GPs with regards to gender and practice type [36]. Moreover, no GPs and PNs were aware that the observations would focus on conversations about smoking.

\subsection{Practice implications}

Our study findings support alternative approaches to smoking cessation care in healthcare settings in which successful implementation of the $5 \mathrm{As}$ is lacking. These alternative approaches include the 'Ask-Advise-Arrange' (A-A-R) or 'AskAdvise-Connect' (A-A-C) approaches [40,41]. These approaches instruct healthcare professionals to routinely ask patients about smoking, advise smokers to quit, and refer (A-A-R) or proactively connect (A-A-C) smokers to a quit line or face-to-face quitsmoking support. As shown by Vidrine et al., significantly more smokers enrolled in quit-smoking treatment following the A-A$\mathrm{C}$ approach (11.4\%) compared to the A-A-R approach $(0.6 \%)$, which is also likely to result in more smokers who successfully quit [41].

Because we found that smokers are least likely to express negative statements about quitting if they are asked about smoking or are advised to quit or if follow-up is arranged; therefore, we recommend GPs to focus on implementing these alternative approaches. This method might reduce the number of barriers impeding implementation, such as the amount of time involved in discussing barriers to quitting. These approaches are also compatible with the lifestyle counselling tasks and skills of PNs. PNs can play an important role in motivating smokers to quit and provide behavioural counselling.

\section{Conflicts of interest statement}

The authors declare that there are no conflicts of interest.

\section{Appendix 1. Role of practice nurses (PNs) in general practice in The Netherlands}

The standard general practice in the Netherlands is composed of approximately 2350 patients, and an average consultation lasts for 
approximately $10 \mathrm{~min}(40)$; these factors result in a considerable time pressure and workload for general practitioners (GPs). Therefore, in 1999, practice nurses (PN) were introduced in Dutch general practice to reduce the workload of GPs and to improve the quality of care for chronically ill patients (41). Currently, PNs are involved in multiple primary prevention activities (e.g., hypertension care) and secondary prevention activities (e.g., routine care for elderly patients and/or patients with diabetes mellitus, asthma, or
COPD). PNs work under the supervision of GPs, manage their consultations independently, and base their clinical practice on guidelines developed by the Dutch College of General Practitioners (NHG) and on healthcare standards that specifically focus on the treatment of chronically ill patients. The collaboration between GPs and PNs provides a strong basis for identifying smokers, motivating them to quit, and delivering effective smoking cessation support.

\section{Appendix 2Coding scheme for speech units}

\begin{tabular}{|c|c|c|c|}
\hline Theme & Category & Subcategory & Example \\
\hline \multicolumn{4}{|l|}{ Professionals } \\
\hline \multirow[t]{16}{*}{5 As } & \multirow[t]{3}{*}{ - Ask } & Smoking status & "Do you smoke?" \\
\hline & & Number of cigarettes & "How many cigarettes do you smoke?" \\
\hline & & Smoking history & "At what age did you start smoking?" \\
\hline & \multirow[t]{2}{*}{ - Advise } & To quit & $\begin{array}{l}\text { "The best prevention for not only your airways but also your coronary } \\
\text { problems is to quit smoking" }\end{array}$ \\
\hline & & To smoke less & $\begin{array}{l}\text { ["The best thing to do is quit smoking"] "but at least cut down on your } \\
\text { smoking" }\end{array}$ \\
\hline & \multirow{9}{*}{$\begin{array}{l}\text { - Assess } \\
\text { - Assist }\end{array}$} & Motivation to quit & “Do you still not feel like quitting?” \\
\hline & & Discuss previous quit attempt & $\begin{array}{l}\text { "You quit smoking for almost a year, did you think of cigarettes every day in } \\
\text { that period?" }\end{array}$ \\
\hline & & Discuss quit plan & $\begin{array}{l}\text { "First, I want you to go home and think about it, "do I want to quit smoking, } \\
\text { am I able to quit smoking'?" }\end{array}$ \\
\hline & & Offer/discuss pharmacotherapy & "Nowadays, we have medication that decreases the craving for cigarettes" \\
\hline & & Discuss advantages of smoking & $\begin{array}{l}\text { "Well, you get some kind of peace from it, especially during hard times, then } \\
\text { you desire your cigarettes." }\end{array}$ \\
\hline & & Discuss risks of smoking & $\begin{array}{l}\text { ".when you continue your smoking, it's far more likely that you will move } \\
\text { from stage } 2-3 \text {, and maybe to stage } 4 \text { " }\end{array}$ \\
\hline & & Discuss advantages of quitting & $\begin{array}{l}\text { "When you say 'I considered quitting', what would be the reasons for this? } \\
\text { What would be the positive side of this?" }\end{array}$ \\
\hline & & Discuss barriers to quitting & "Maybe it is more like a habit, is that right?" \\
\hline & & Discuss support options & $\begin{array}{l}\text { "We talked about it before, I also provide consultations for smoking } \\
\text { cessation, so if you think you would like to quit smoking, then we could do } \\
\text { that together..." }\end{array}$ \\
\hline & \multirow[t]{2}{*}{ - Arrange } & Ask permission to discuss smoking next time & "Do you mind if we discuss your smoking again next time?" \\
\hline & & Plan (telephone) follow-up & "Yes, we'll discuss that next time, do you come back then?" \\
\hline \multirow{23}{*}{$\begin{array}{l}\text { Patients } \\
\text { Negative statement } \\
\text { about smoking } \\
\text { cessation }\end{array}$} & \multirow{23}{*}{$\begin{array}{l}\text { - Barriers to quit } \\
\text { - Reasons for relapse } \\
\text { - Advantages of } \\
\text { smoking } \\
\text { Disadvantages of } \\
\text { quitting }\end{array}$} & & \\
\hline & & Habit & "Meanwhile, it has become a habit after all of these years" \\
\hline & & Lack of motivation/discipline & $\begin{array}{l}\text { "I quit smoking for a year, but I started again. I think it depends on your } \\
\text { overall lifestyle, maybe a little unhealthy. I would like to improve that... but } \\
\text { that will require some discipline of course..." }\end{array}$ \\
\hline & & Denial of consequences & $\begin{array}{l}\text { "Maybe when you're smoking a package each day, then I should think 'yes, } \\
\text { maybe you should cut down a little on your smoking..." }\end{array}$ \\
\hline & & Social environment & "Someday I have to quit, but my wife is a smoker as well." \\
\hline & & Stress & ".but on the other hand, it helps to reduce my stress" \\
\hline & & (Fear of) weight gain & $\begin{array}{l}\text { "Yes, I would like to quit smoking, but I'm worried about my weight, to gain } \\
\text { weight again..." }\end{array}$ \\
\hline & & Previous quit attempt failed & "I already tried it 7 or 8 times..." \\
\hline & & Not the right time & $\begin{array}{l}\text { "When I quit I'm not very pleasant, and we bought a new house, the move } \\
\text { will be on the 4th" }\end{array}$ \\
\hline & & Addiction & "That's the addiction to nicotine of course, it's the same as with alcohol" \\
\hline & & Smoking is tasteful/enjoyable & "It's stupid, but I really like it, especially on the weekends after breakfast. .." \\
\hline & & Satisfied smoker & "I'm okay with being a smoker" \\
\hline & & Lack of distraction/daytime activities & "I sit at home for 3 weeks... and then you'll start smoking again" \\
\hline & & Lack of self-confidence & "I want to quit, but I really don't know how" \\
\hline & & Related to pharmacotherapy (e.g., costs) & $\begin{array}{l}\text { "I once did a treatment, I had to continue smoking for } 10 \text { days and after the } \\
\text { pill it would be all over... but it did not work..." }\end{array}$ \\
\hline & & No complaints of smoking & ["What would be reasons for quitting smoking?"] "Well, I feel fine actually" \\
\hline & & Long-time smoker & $\begin{array}{l}\text { ["Do you think about quitting or not?"] "Well, what do you want? I'm } 70 \text {. I } \\
\text { only have a few years left so..." }\end{array}$ \\
\hline & & Smoking cessation is not profitable & "When I don't smoke I still have those complaints" \\
\hline & & Stigma & $\begin{array}{l}\text { "Nowadays, if you have a sore knee they will ask you if you're smoking. . as } \\
\text { if you sprain your ankle because of smoking. Well, that makes me furious" }\end{array}$ \\
\hline & & Smoking is the only thing left & "I'll never give up smoking, it's the only thing I still have" \\
\hline & & Withdrawal symptoms & "In the morning I have to smoke a cigarette again, to feel fine again..." \\
\hline & & Psychological complaints & $\begin{array}{l}\text { "I quit smoking, but now I go to a psychologist again for depression and I } \\
\text { started smoking again." }\end{array}$ \\
\hline & & Smoker identity & "I don't see myself refraining from smoking actually...' \\
\hline
\end{tabular}


(Continued)

\begin{tabular}{|c|c|c|c|}
\hline Theme & Category & Subcategory & Example \\
\hline \multirow{11}{*}{$\begin{array}{l}\text { Positive } \\
\text { statements } \\
\text { about smoking } \\
\text { cessation }\end{array}$} & \multirow[t]{11}{*}{ - Motivators to quit } & Health concerns & $\begin{array}{l}\text { "The main reason I would say is 'it's not good for your health', that would be } \\
\text { the reason to quit" }\end{array}$ \\
\hline & & Social environment & $\begin{array}{l}\text { "I will read that [leaflet], then we can look at it together at home, maybe } \\
\text { he'll also say 'when you quit, I will quit' }\end{array}$ \\
\hline & & Health of children & $\begin{array}{l}\text { "My daughter is pregnant, so nobody smokes anymore. I think I should quit, } \\
\text { yes." }\end{array}$ \\
\hline & & Fear for disease/illness & $\begin{array}{l}\text { "However, I'm actually not really afraid of getting lung cancer, but more of } \\
\text { getting something here ... [larynx]" }\end{array}$ \\
\hline & & Quit-smoking advice of health professional & "Yes, you're absolutely right. .. but, yes well... then I shall do that" \\
\hline & & Smoke-free legislation & $\begin{array}{l}\text { "Once I was in prison for } 18 \text { months...that was hard, } 24 \mathrm{~h} \text { inside and not } \\
\text { allowed to smoke...I then quit smoking" }\end{array}$ \\
\hline & & Costs & $\begin{array}{l}\text { "I've already thought about it for a while because, well cigarettes are } \\
\text { expensive" }\end{array}$ \\
\hline & & Smoke smell/taste & “....and they [cigarettes] don’t taste very special anymore” \\
\hline & & Sufficient distraction/daytime activities & $\begin{array}{l}\text { "When I'm busy, then it's easy. For example, tomorrow my grandchild will } \\
\text { visit me, then it's going perfect" }\end{array}$ \\
\hline & & Sufficient motivation/discipline & "I definitely want to quit smoking" \\
\hline & & Positive consequences of quitting & $\begin{array}{l}\text { "I often have good results if I refrain from smoking for a while, I feel } \\
\text { mentally better then" }\end{array}$ \\
\hline \multicolumn{4}{|l|}{$\begin{array}{l}\text { Professionals } \\
\text { and patients }\end{array}$} \\
\hline \multirow[t]{10}{*}{ Other speech units } & \multicolumn{2}{|c|}{ - Other, smoke-related Question } & "So, coffee and smoking are two risk factors?" [patient] \\
\hline & & Answer & "I smoke one pack a day" [patient] \\
\hline & & Provision information & "People who smoke... this has its effect on the vocal cords" [professional] \\
\hline & & Confirmation & ["You are a smoker, that's not good"] "No, that's right" [patient] \\
\hline & & Other & $\begin{array}{l}\text { [I don't think you are a good example for your kids this way] "Well, I shall } \\
\text { talk about it with my wife" [patient] }\end{array}$ \\
\hline & \multirow{5}{*}{$\begin{array}{l}\text { - Other, non-smoke- } \\
\text { related }\end{array}$} & Question & "Do you have a fever?" [professional] \\
\hline & & Answer & "This side is much more painful" [patient; during physical examination] \\
\hline & & Provision information & $\begin{array}{l}\text { "With regards to your cholesterol, according to this table, you are still } \\
\text { within the normal risk boundaries" [professional] }\end{array}$ \\
\hline & & Confirmation & [I can give you something to inhale] "Yes" [patient] \\
\hline & & Other & "Thank you, see you next time" [patient] \\
\hline
\end{tabular}

Appendix 3. Simplified example of transitional probabilities

\begin{tabular}{llllll}
\hline & & Lag $1-3$ & & \multirow{2}{*}{ Total } \\
\cline { 3 - 4 } & & A & B & C & \\
\hline \multirow{2}{*}{ Lag 0 } & A & $0.00(0 / 7)$ & $0.43(3 / 7)$ & $0.57(4 / 7)$ & $1.00(7 / 7)$ \\
& B & $0.40(2 / 5)$ & $0.00(0 / 5)$ & $0.60(3 / 5)$ & $1.00(5 / 5)$ \\
& C & $0.63(5 / 8)$ & $0.25(2 / 8)$ & $0.12(1 / 8)$ & $1.00(8 / 8)$ \\
\hline
\end{tabular}

\section{References}

[1] Chavannes NH, Kaper J, Frijling BD, Van der Laan JR, Jansen PWM, Guerrouj S, et al., Dutch College of General Practitioners Guideline for Smoking Cessation. NHG-Standaard Stoppen met roken. Huisarts Wet 2007;50(7):306-14.

[2] Fiore MC, Wetter DW, Bailey WC, Blennett G, Cohen SJ, Dorfman SF, et al., The Agency for Health Care Policy and Research Smoking Cessation. Clinical practice guideline. J Am Med Assoc 1996;275(16):1270-80.

[3] Pieterse ME, Seydel ER, de Vries H, Mudde AN, Kok GJ. Effectiveness of a minimal contact smoking cessation program for Dutch general practitioners: a randomized controlled trial. Prev Med 2001;32(2):182-90.

[4] Puschel K, Thompson B, Coronado G, Huang Y, Gonzalez L, Rivera S. Effectiveness of a brief intervention based on the ' $5 A^{\prime}$ ' model for smoking cessation at the primary care level in Santiago, Chile. Health Promot Int 2008;23(3):240-50.

[5] Takahashi K, Saso H, Saka H, Saso H, Iwata M, Hashimoto I, et al. A pilot study on inducement of smoking cessation by a simple 5A (asking, advice, assess, assist, and arrange) approach at outpatient clinics. Asian Pac J Cancer Prev 2006;7(1):131-5.

[6] Feenstra TL, Hamberg-van Reenen HH, Hoogenveen RT, Rutten-van Mölken MP. Cost-effectiveness of face-to-face smoking cessation interventions: a dynamic modeling study. Value Health 2005;8(3):178-90.

[7] Coleman T, Murphy E, Cheater F. Factors influencing discussion of smoking between general practitioners and patients who smoke: a qualitative study. $\mathrm{Br} \mathrm{J}$ Gen Pract 2000;50(452):207-10.

[8] Coleman T, Cheater F, Murphy E. Qualitative study investigating the process of giving anti-smoking advice in general practice. Patient Educ Couns 2004;52: 159-63.

[9] Stead M, Angus K, Holme I, Cohen D, Tait G. Factors influencing European GPs' engagement in smoking cessation: a multi-country literature review. Br J Gen Pract 2009;59(566):682-90.
[10] Vogt F, Hall S, Marteau TM. General practitioners' and family physicians negative beliefs and attitudes towards discussing smoking cessation with patients: a systematic review. Addiction 2005;100(10):1423-31.

[11] Jansink R, Braspenning J, van der Weijden T, Elwyn G, Grol R. Primary care nurses struggle with lifestyle counseling in diabetes care: a qualitative analysis. BMC Fam Pract 2010;11(41). http://dx.doi.org/10.1186/1471-2296-11-41.

[12] Geense WW, van de Glind IM, Visscher TL, van AT. Barriers, facilitators and attitudes influencing health promotion activities in general practice: an explorative pilot study. BMC Fam Pract 2013;14(20). http://dx.doi.org/10. 1186/1471-2296-14-20.

[13] Ulbricht S, Klein G, Haug S, Gross B, Rumpf HJ, John U, et al. Smokers' expectations toward the engagement of their general practitioner in discussing lifestyle behaviors. J Health Commun 2011;16(2):135-47.

[14] Francis N, Rollnick S, McCambridge J, Butler C, Lane C, Hood K. When smokers are resistant to change: experimental analysis of the effect of patient resistance on practitioner behaviour. Addiction 2005;100(8) $1175-82$.

[15] Young JM, Ward JE. Implementing guidelines for smoking cessation advice in Australian general practice: opinions, current practices, readiness to change and perceived barriers. Fam Pract 2001;18(1):14-20.

[16] de Korte D, Nagelhout GE, Willemsen MC. Stoppen-met-rokenadvisering door huisartsen in Nederlands 2001-2009. Smoking cessation advisement in Dutch general practice 2001-2009 The Hague, the Netherlands: STIVORO - for a smoke-free future; 2010.

[17] Pilnick A, Coleman T. I'll give up smoking when you get me better: patients' resistance to attempts to problematise smoking in general practice (GP) consultations. Soc Sci Med 2003;57(1):135-45.

[18] Coleman T, Stevenson K, Wilson A. Using content analysis of video-recorded consultations to identify smokers' readiness and resistance towards stopping smoking. Patient Educ Couns 2000;41(3):305-11.

[19] The Dutch National Association of General Practitioners [LHV]. Practice nurse. Competence profile and requirements;Praktijkondersteuner. Competentieprofiel en eindtermen 2010.

[20] Ellerbeck EF, Ahluwalia JS, Jolicoeur DG, Gladden J, Mosier MC. Direct observation of smoking cessation activities in primary care practice. J Fam Pract $2001 ; 50(8): 688-93$.

[21] Humair JP, Ward J. Smoking-cessation strategies observed in videotaped general practice consultations. Am J Prev Med 1998;14(1):1-8.

[22] Lorencatto F, West R, Christopherson C, Michie S. Assessing fidelity of delivery of smoking cessation behavioural support in practice. Implement Sci 2013;8(40). http://dx.doi.org/10.1186/1748-5908-8-40.

[23] Milder IE, Blokstra A, de Groot J, van Dulmen S, Bemelmans WJ. Lifestyle counseling in hypertension-related visits: analysis of video-taped general 
practice visits. BMC Fam Pract 2008;9(58). http://dx.doi.org/10.1186/14712296-9-58.

[24] Moran J, Bekker H, Latchford G. Everyday use of patient-centred, motivationa techniques in routine consultations between doctors and patients with diabetes. Patient Educ Couns 2008;73(2):224-31.

[25] Noordman J, Verhaak P, van Dulmen S. Discussing patient's lifestyle choices in the consulting room: analysis of GP-patient consultations between 1975 and 2008 BMC Fam Pract 2010;11(87). http://dx.doi.org/10.1186/1471-2296-11-87.

[26] Coleman T. Using video-recorded consultations for research in primary care: advantages and limitations. Fam Pract 2000;17(5):422-7.

[27] Noordman J, Verhaak P, van Beljouw I, van Dulmen S. Consulting room computers and their effect on general practitioner-patient communication. Fam Pract 2010;27(6):644-51.

[28] Noordman J, van der Lee I, Nielen M, Vlek H, van der Weijden T, van Dulmen S. Do trained practice nurses apply motivational interviewing techniques in primary care consultations? J Clin Med Res 2012;4(6):393-401.

[29] Central Committee on Research involving Human Subjects. The review system in the Netherlands. CCMO; 2012.

[30] Bensing JM, Verheul W, Jansen J, Langewitz WA. Looking for trouble: the added value of sequence analysis in finding evidence for the role of physicians in patients' disclosure of cues and concerns. Med Care 2010;48(7):583-8.

[31] Bakeman R, Gottman JM. Observing interaction: an introduction to sequential analysis. 2nd ed. Cambridge: Cambridge University Press; 1997.

[32] McComas JJ, Moore T, Dahl N, Hartman E, Hoch J, Symons F. Calculating contingencies in natural environments: issues in the application of sequential analysis. J Appl Behav Anal 2009;42(2):413-23.
[33] Quera V, Bakeman R. Quantification strategies in behavioral observation research. In: Brooks, editor. Behavioral observation: technology and application in developmental disabilities. 2000. p. 297-315. Baltimore.

[34] Noordman J. Lifestyle counseling by physicians and practice nurses in primary care. An analysis of daily practice. Utrecht: Netherlands Institute for Health Services Research; 2013.

[35] Voogdt-Pruis HR, van Ree JW, Gorgels AP, Beusmans GH. Adherence to a guideline on cardiovascular prevention: a comparison between general practitioners and practice nurses. Int J Nurs Stud 2011;48(7):798-807.

[36] Noordman J, Koopmans B, Korevaar JC, van der Weijden T, van Dulmen S. Exploring lifestyle counselling in routine primary care consultations: the professionals' role. Fam Pract 2012;30(3):332-40.

[37] Werner JJ, Lawson PJ, Panaite V, Step MM, Flocke SA. Comparing primary care physicians' smoking cessation counseling techniques to motivational interviewing. J Addict Med 2013;7(2):139-42.

[38] Miller WR, Rollnick S. Motivational interviewing: preparing people to change addictive behavior. New York: Guildford; 1991.

[39] Williams K, Herman R, Bontempo D. Comparing audio and video data for rating communication. West J Nurs Res 2013;35(8):1060-73.

[40] Berndt NC, Bolman C, de Vries H, Segaar D, van Boven I, Lechner L. Smoking cessation treatment practices: recommendations for improved adoption on cardiology wards. J Cardiovasc Nurs 2013;28(1):35-47.

[41] Vidrine JI, Shete S, Cao Y, Greisinger A, Harmonson P, Sharp B, et al. Askadvise-connect: a new approach to smoking treatment delivery in health care settings. J Am Med Assoc Intern Med 2013;173(6):458-64. 